\title{
Electron Diffraction Investigation on the Molecular Structure of 1,6-Dioxa-6a-thiapentalene and 2,5-Diaza-1,6-dioxa-6a- thiapentalene
}

\author{
Kolbjørn Hagen, ${ }^{a}$ Leif J. Sæethre, ${ }^{b}$ Carl Th. Pedersen ${ }^{c}$ and Thorvald Pedersen ${ }^{d}$
}

aDepartment of Chemistry, University of Trondheim, AVH, N-7055 Trondheim, 'Department of Chemistry, Institute of Mathematical and Physical Sciences, University of Tromsø, N-9001 Troms $ø$, Norway, 'Department of Chemistry, Odense University, DK-5230 Odense M and ${ }^{\mathrm{d} C h e m i c a l}$ Laboratory V, The H. C. Ørsted Institute, Universitetsparken 5, DK-2100 Copenhagen Ø, Denmark

\begin{abstract}
Hagen, K., Sæthre, L. J., Pedersen, C. T. and Pedersen, T., 1988. Electron Diffraction Investigation on the Molecular Structure of 1,6-Dioxa-6a-thiapentalene and 2,5-Diaza-1,6-dioxa-6a-thiapentalene. - Acta Chem. Scand., Ser. A 42: 71-78.

The molecular structures of 1,6-dioxa-6a-thiapentalene and 2,5-diaza-1,6-dioxa-

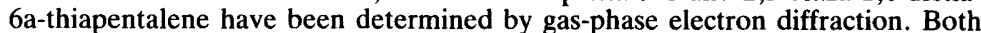
molecules are planar with symmetry $C_{2 v}$. The $\mathrm{N}$-ring substitution shortens the $\mathrm{S}-\mathrm{O}$ bonds and gives a more pronounced double bond character for the $\mathrm{C}-\mathrm{S}$ bond. The vibrational amplitudes of the $\mathrm{S}-\mathrm{O}$ bonds are directly related to the observed bond lengths in the three-center sequence. Values of bond distances $\left(r_{\mathrm{a}}\right)$ and valence angles $\left(\angle_{\alpha}\right)$ based on $C_{2 v}$ symmetry, with estimated $2 \sigma$ uncertainties, are: 1,6-dioxa-6a-thiapentalene: $r(\mathrm{C}-\mathrm{H})=1.097(22), r(\mathrm{C}-\mathrm{O})=1.310(9)$, $r\left(\mathrm{C}_{2}-\mathrm{C}_{3}\right)=1.375(17), r\left(\mathrm{C}_{3}-\mathrm{C}_{3 \mathrm{a}}\right)=1.397(15), r(\mathrm{C}-\mathrm{S})=1.752(16), r(\mathrm{~S}-\mathrm{O})=$ $1.865(9) \AA, \angle C_{3}-C_{3 a}-S=112.8(5), \angle C_{2}-C_{3}-C_{3 a}=113.2(6)$ and $\angle O-C_{2}-C_{3}=$ 115.6(7) ${ }^{\circ}$. 2,5-diaza-1,6-dioxa-6a-thiapentalene: $r(\mathrm{C}-\mathrm{H})=1.114(42), r(\mathrm{~N}-\mathrm{C})=$ $1.329(32), r(\mathrm{O}-\mathrm{N})=1.325(26), r(\mathrm{C}-\mathrm{C})=1.411(10), r(\mathrm{C}-\mathrm{S})=1.696(12), r(\mathrm{~S}-\mathrm{O})$ $=1.827(8) \AA, \angle \mathrm{N}-\mathrm{C}-\mathrm{C}=115.3(8), \angle \mathrm{O}-\mathrm{N}-\mathrm{C}=111.0(4)$ and $\angle \mathrm{C}-\mathrm{C}-\mathrm{S}=$ $112.9(5)^{\circ}$.
\end{abstract}

\section{Dedicated to Professor Olav Foss on his 70th birthday}

The molecular structures of 1,6-dioxa-6a-thiapentalene (hereafter denoted DOTP, Fig. 1A) and 2,5-diaza-1,6-dioxa-6a-thiapentalene (DADOTP, Fig. 1B) have been the subjects of several investigations. It is especially the bonding properties in the $\mathrm{O}-\mathrm{S}-\mathrm{O}$ sequence which have been of interest. In the related molecule 1,6,6a-trithiapentalene (TTP), theoretical calculations, ${ }^{1-2}$ and electron diffraction ${ }^{3}$ and ESCA studies ${ }^{4}$ have indicated that the $\mathrm{S}-\mathrm{S}-\mathrm{S}$ system has a flat minimum around the $S-S$ equilibrium distance. In the electron diffraction study this property was revealed as a larger vibrational amplitude for the $S-S$ bond than for the non-bonded $\mathrm{S}---\mathrm{S}$ distance. ${ }^{3}$

The bonding in the $\mathrm{O}-\mathrm{S}-\mathrm{O}$ sequence is expected to be similar to the $\mathrm{S}-\mathrm{S}-\mathrm{S}$ bonding. X-ray crystallographic studies on DADOTP ${ }^{5}$ and the 2,5-dimethyl derivative of $\mathrm{DOTP}^{6}$ show that the $\mathrm{S}-\mathrm{O}$ bonds are longer than single bonds and that the molecules possess $C_{2 v}$ symmetry in the solid state. Microwave (MW) spectroscopy ${ }^{7}$ of DADOTP indicates that the $C_{2 v}$ symmetry is also preserved in the gas phase, and for DOTP both MW spectroscopy ${ }^{8}$ and a ${ }^{1} \mathrm{H}$ NMR study in the nematic phase ${ }^{9}$ lead to the same conclusion.

In this paper we report the results of an electron diffraction investigation of DOTP and DADOTP in which the rotational constants obtained from MW spectroscopy have been included as experimental data in the analysis. The structure determinations were carried out in order to provide accurate bonding parameters for both molecules in the gas phase. Of particular interest is the effect of $\mathrm{N}$-ring substitution on the $\mathrm{O}-\mathrm{S}-\mathrm{O}$ bonding. Because of the weak bonding in the threecenter sequence, the bond lengths are very sensitive to substituent effects. In fact, the molecular system provides a unique opportunity to observe 


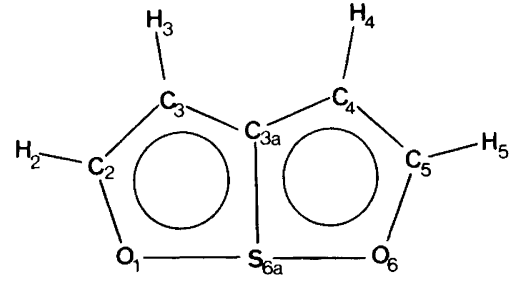

A

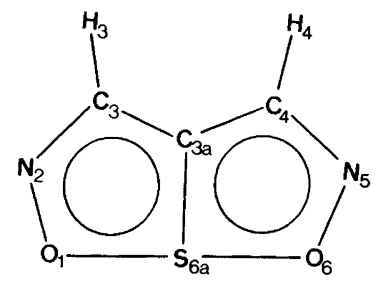

$B$

Fig. 1. Molecular models of 1,6-dioxa-6a-thiapentalene (A) and 2,5-diaza-1,6-dioxa-6a-thiapentalene (B) with atom numbering.

effects that normally are too small to be detected. For DADOTP, $a b$ initio calculations indicate dramatic polarization of the thiapentalene system as a result of $\mathrm{N}$-ring substitution, ${ }^{10}$ and the molecular bonding is expected to be significantly perturbed. This is indeed observed experimentally, since both the S-O and C-S bonds are shortened appreciably.

The effect of N-ring substitution is also expected to influence the vibrational amplitude of the $\mathrm{S}-\mathrm{O}$ bond. ESCA studies on DADOTP show that the weak $\mathrm{S}-\mathrm{O}$ bonds are revealed as exceptionally broad $\mathrm{O} 1 s$ lines for this molecule, and that the broadening is related to the vibrational amplitude of the S-O bond, i.e. to the width of the $\mathrm{O}-\mathrm{S}-\mathrm{O}$ potential. ${ }^{11}$ Similar results are obtained for the S-S bonds in 1,6,6a-trithiapentalene. ${ }^{12}$

The vibrational amplitudes for the $\mathrm{S}-\mathrm{O}$ bonds in DOTP and DADOTP, and for the S-S bonds in TTP, can be obtained directly from the electron diffraction studies of these compounds. One of the objects of this investigation was to correlate the vibrational amplitudes of the $\mathrm{S}-\mathrm{O}$ and $\mathrm{S}-\mathrm{S}$ bonds with the observed bond lengths in the three-center sequence.

\section{Experimental}

DOTP was prepared according to the method of Reid and Webster, ${ }^{13}$ and DODATP was prepared as described in Ref. 7. Electron diffraction photographs were recorded with a Balzers Eldigraph KDG-2 $2^{14-15}$ on Kodak Electron Image plates. The electron wavelength was calibrated against benzene. ${ }^{16}$ Optical densities were measured with a Joyce Loebl microdensitometer. For DOTP, a nozzle temperature of $85^{\circ} \mathrm{C}$ was used. Four

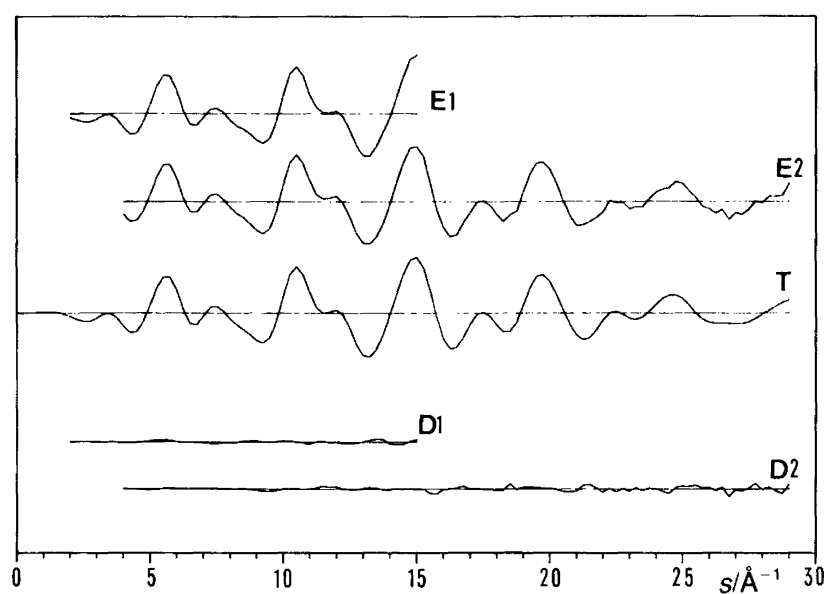

72
Fig. 2. Intensity curves $s I_{m}(s)$ for 1,6-dioxa-6a-thiapentalene. Experimental curves $(E 1, E 2)$ are averages of all plates for the two camera distances. Theoretical curve ( $T$ ) was calculated from the structural parameters in Table 1. Difference curves (D1, D2) are E-T. 


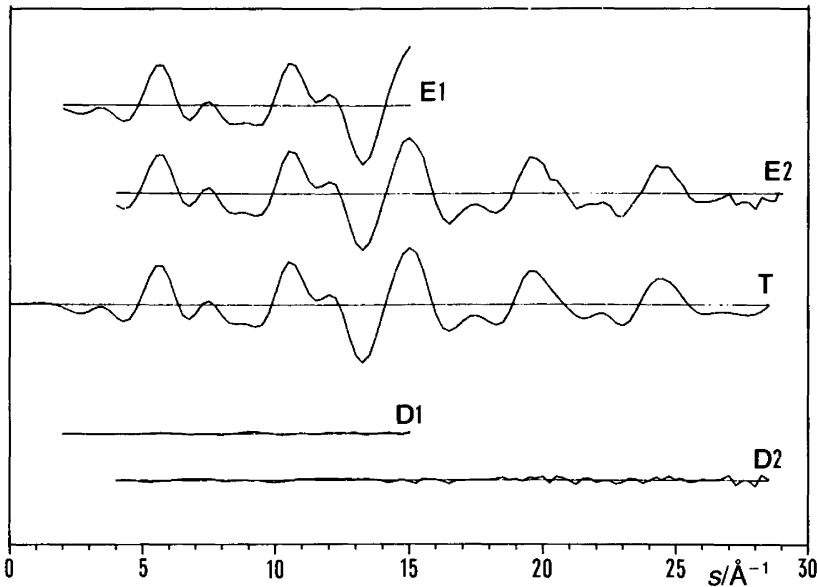

Fig. 3. Intensity curves $s I_{m}(s)$ for 2,5-diaza-1,6-dioxa-6a-thiapentalene. Experimental curves (E1, E2) are averages of all plates for the two camera distances. Theoretical curve $(T)$ was calculated from the structural parameters in Table 2. Difference curves (D1, D2) are $\mathrm{E}-\mathrm{T}$.

Fig. 4. Radial distribution curves for 1,6-dioxa-6a-thiapentalene showing experimental $(E)$, theoretical $(T)$ and difference (D) curves. The curves were calculated from the curves of Fig. 2 after multiplication by $Z_{C} Z_{O} / f_{C} f_{O} \exp$ $\left(-0.002 s^{2}\right)$ and using theoretical data for the unobserved area $s<2.0 \AA^{-1}$. The vertical lines indicate the position of the interatomic distances, height being proportional to weight of distance. Nonbonded distances involving $\mathrm{H}$ are not shown.

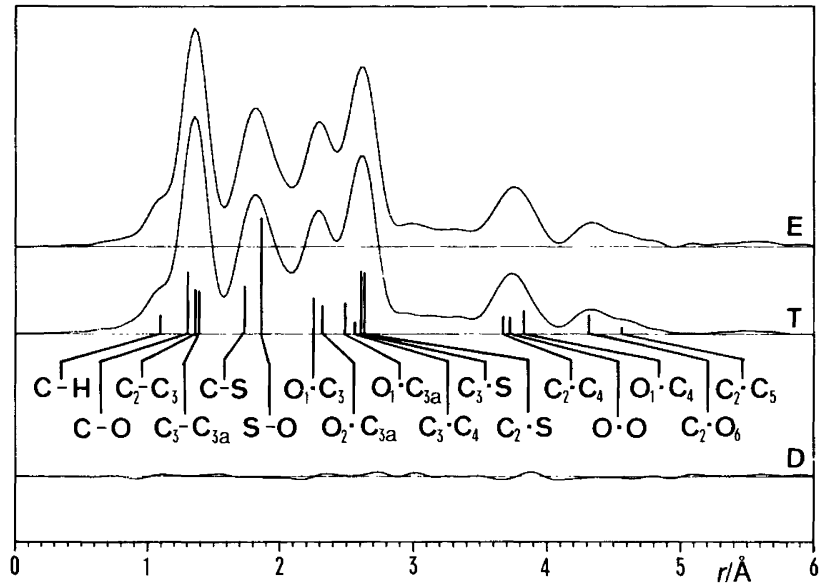

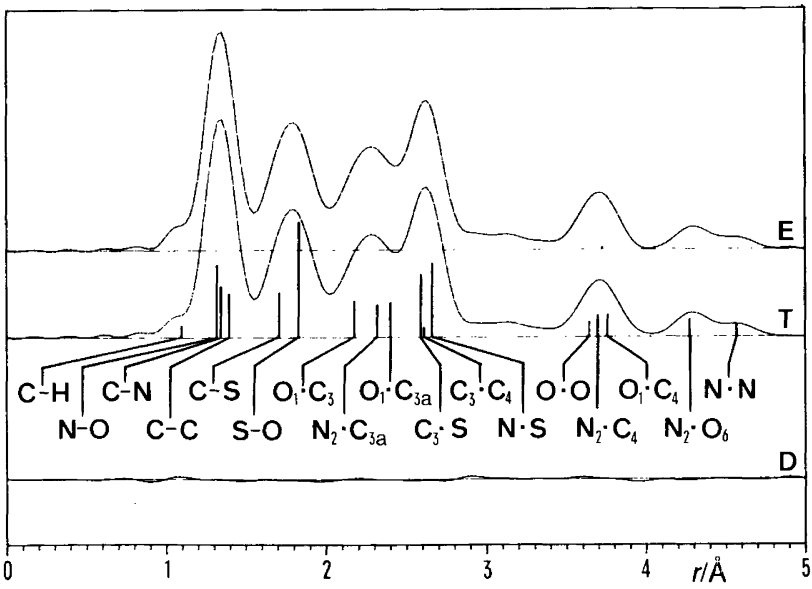

Fig. 5. Radial distribution curves for 2,5-diaza-1,6-dioxa-6a-thiapentalene showing experimental (E), theoretical (T) and difference (D) curves. The curves were calculated from the curves of Fig. 3 after multiplication by $Z_{C} Z_{O} / f_{C} f_{O} \exp$ $\left(-0.002 s^{2}\right)$ and using theoretical data for the unobserved area $s<2.0 \AA^{-1}$. The vertical lines indicate the position of the interatomic distances, height being proportional to weight of distance. Nonbonded distances involving $\mathrm{H}$ are not shown. 
Table 1. Final structural parameters for 1,6-dioxa-6athiapentalene. ${ }^{a}$

\begin{tabular}{lcl}
\hline Parameter & $r_{\mathrm{a}}, \angle_{\alpha}$ & $l^{b}$ \\
\hline$r(\mathrm{C}-\mathrm{H})$ & $1.097(22)$ & 0.077 \\
$r(\mathrm{C}-\mathrm{O})$ & $1.310(9)$ & 0.047 \\
$<r(\mathrm{C}-\mathrm{C})>$ & $1.386(5)$ & \\
$\Delta r(\mathrm{C}-\mathrm{C})$ & $0.022(30)$ & \\
$r(\mathrm{C}-\mathrm{S})$ & $1.752(16)$ & 0.059 \\
$\angle \mathrm{C}_{3}-\mathrm{C}_{3 a}-\mathrm{S}_{6 a}$ & $112.8(5)$ & \\
$\angle \mathrm{C}_{2}-\mathrm{C}_{3}-\mathrm{H}$ & {$[125.1]^{c}$} & \\
$\angle \mathrm{C}_{3}-\mathrm{C}_{2}-\mathrm{H}$ & {$[125.1]^{c}$} & \\
$\angle \mathrm{C}_{2}-\mathrm{C}_{3}-\mathrm{C}_{3 a}$ & $113.2(6)$ & \\
$\angle \mathrm{O}-\mathrm{C}_{2}-\mathrm{C}_{3}$ & $115.6(7)$ &
\end{tabular}

Dependent parameters

\begin{tabular}{|c|c|c|}
\hline$\angle \mathrm{O}-\mathrm{S}-\mathrm{O}$ & $174.3(6)$ & \\
\hline$\angle \mathrm{C}-\mathrm{O}-\mathrm{S}$ & $111.2(6)$ & \\
\hline$\angle \mathrm{C}-\mathrm{S}-\mathrm{O}$ & $87.1(3)$ & \\
\hline$r(\mathrm{~S}-\mathrm{O})$ & $1.865(9)$ & $0.104(11)$ \\
\hline$r\left(\mathrm{C}_{2}-\mathrm{C}_{3}\right)$ & $1.375(17)$ & 0.046 \\
\hline$r\left(C_{3}-C_{3 a}\right)$ & $1.397(15)$ & 0.049 \\
\hline$r\left(\mathrm{O}_{1} \cdots \mathrm{H}_{2}\right)$ & $2.082(18)$ & 0.108 \\
\hline$r\left(\mathrm{C}_{3} \cdots \mathrm{H}_{2}\right)$ & $2.186(21)$ & 0.107 \\
\hline$r\left(\mathrm{~S} \cdots \mathrm{H}_{3}\right)$ & $3.684(12)$ & 0.100 \\
\hline$r\left(\mathrm{O}_{1} \cdots \mathrm{H}_{3}\right)$ & $3.311(12)$ & 0.098 \\
\hline$r\left(\mathrm{O}_{1} \cdots \mathrm{H}_{4}\right)$ & $4.667(16)$ & 0.127 \\
\hline$r\left(\mathrm{O}_{1} \cdots \mathrm{H}_{5}\right)$ & $5.414(16)$ & 0.112 \\
\hline$r\left(\mathrm{C}_{2} \cdots \mathrm{H}_{4}\right)$ & $4.250(14)$ & 0.141 \\
\hline$r\left(\mathrm{C}_{2} \cdots \mathrm{H}_{5}\right)$ & $5.633(18)$ & 0.101 \\
\hline$r\left(\mathrm{C}_{3} \cdots \mathrm{H}_{4}\right)$ & $2.946(29)$ & 0.147 \\
\hline$r\left(\mathrm{C}_{3} \cdots \mathrm{H}_{5}\right)$ & $4.701(16)$ & 0.105 \\
\hline$r\left(\mathrm{C}_{3 a} \cdots \mathrm{H}_{5}\right)$ & $3.363(13)$ & 0.100 \\
\hline$r\left(\mathrm{O}_{1} \cdots \mathrm{C}_{3}\right)$ & $2.272(6)$ & 0.058 \\
\hline$r\left(O_{1} \cdots C_{3 a}\right)$ & $2.492(9)$ & 0.074 \\
\hline$r\left(O_{1} \cdots C_{4}\right)$ & $3.842(9)$ & 0.086 \\
\hline$r(0 \cdots 0)$ & $3.722(11)$ & 0.102 (11) \\
\hline$r\left(\mathrm{C}_{2} \cdots \mathrm{C}_{4}\right)$ & $3.685(10)$ & 0.076 \\
\hline$r\left(\mathrm{C}_{2} \cdots \mathrm{O}_{6}\right)$ & $4.318(10)$ & 0.083 \\
\hline$r\left(\mathrm{C}_{2} \cdots \mathrm{C}_{3 \mathrm{a}}\right)$ & $2.312(10)$ & 0.065 \\
\hline$r\left(\mathrm{C}_{2} \cdots \mathrm{C}_{5}\right)$ & $4.548(13)$ & 0.070 \\
\hline$r\left(\mathrm{C}_{2} \cdots \mathrm{S}\right)$ & $2.638(8)$ & 0.064 \\
\hline$r\left(\mathrm{C}_{3} \cdots \mathrm{C}_{4}\right)$ & $2.572(22)$ & 0.063 \\
\hline$r\left(\mathrm{C}_{3} \cdots \mathrm{S}\right)$ & $2.627(7)$ & 0.064 \\
\hline
\end{tabular}

${ }^{a}$ Distances $\left(r_{\mathrm{a}}\right)$ and amplitudes $(I)$ in $\AA$, angles $\left(\angle_{\alpha}\right)$ in degrees. Values in parentheses are estimated $2 \sigma$ values. ${ }^{b}$ Quantities in braces refined as a group. ${ }^{c}$ Assumed values.

plates from the measurements with the long (497.87 mm) and four from measurements with the short $(248.02 \mathrm{~mm})$ nozzle-to-plate distance were selected for analysis. For DADOTP the nozzle-temperature was $123^{\circ} \mathrm{C}$, and four plates from measurements with each of the two nozzleto-plate distances were used. The data were reduced in the usual way, ${ }^{17-18}$ and a calculated background ${ }^{19}$ was subtracted from the data for each plate to yield the experimental molecular intensity distribution in the form $s I_{\mathrm{m}}(s)$. Data for the long and short camera distances were obtained over the ranges $2.00 \leq s \leq 15.00$ and $4.00 \leq s \leq$ $28.50 \AA^{-1}$, respectively, at intervals $\Delta s=0.25$ $\AA^{-1}$. The average experimental intensity curves

Table 2. Final structural parameters for 2,5-diaza-1,6-dioxa-6a-thiapentalene. ${ }^{a}$

\begin{tabular}{lcl}
\hline Parameter & $r_{\mathrm{a}}, \angle_{\alpha}$ & $I^{b}$ \\
\hline$r(\mathrm{C}-\mathrm{H})$ & $1.114(42)$ & 0.077 \\
$r(\mathrm{~N}-\mathrm{O})$ & $1.325(26)$ & 0.048 \\
$r(\mathrm{C}-\mathrm{N})$ & $1.329(32)$ & 0.045 \\
$r(\mathrm{C}-\mathrm{C})$ & $1.411(10)$ & 0.052 \\
$r(\mathrm{C}-\mathrm{S})$ & $1.696(12)$ & 0.063 \\
$\angle \mathrm{N}-\mathrm{C}-\mathrm{H}$ & $120.5(90)$ & \\
$\angle \mathrm{N}-\mathrm{C}-\mathrm{C}$ & $115.3(8)$ & \\
$\angle \mathrm{O}-\mathrm{N}-\mathrm{C}$ & $111.0(4)$ & \\
$\angle \mathrm{C}-\mathrm{C}-\mathrm{S}$ & $112.9(5)$ &
\end{tabular}

Dependent parameters

\begin{tabular}{|c|c|c|}
\hline $\begin{array}{l}\angle \mathrm{O}-\mathrm{S}-\mathrm{O} \\
\angle \mathrm{S}-\mathrm{O}-\mathrm{N} \\
\angle \mathrm{O}-\mathrm{S}-\mathrm{C}\end{array}$ & $\begin{array}{r}172.3(8) \\
114.6(8) \\
851(6)\end{array}$ & \\
\hline $\begin{array}{l}\angle \mathrm{O}-\mathrm{S}-\mathrm{C} \\
\mathrm{r}(\mathrm{S}-\mathrm{O})\end{array}$ & $\begin{array}{l}85.1(6) \\
1827(8)\end{array}$ & $0.086(6)$ \\
\hline$r\left(\mathrm{~N}_{2} \cdots \mathrm{H}_{3}\right)$ & $2.116(95)$ & 0.100 \\
\hline$r\left(\mathrm{C}_{3 a} \cdots H\right)$ & $2.228(105)$ & 0.117 \\
\hline$r(S \cdots H)$ & $3.655(39)$ & 0.108 \\
\hline$r\left(\mathrm{O}_{1} \cdots \mathrm{H}_{3}\right)$ & $3.220(3)$ & 0.096 \\
\hline$r\left(\mathrm{O}_{1} \cdots \mathrm{H}_{4}\right)$ & $4.621(73)$ & 0.138 \\
\hline$r\left(\mathrm{~N}_{2} \cdots \mathrm{H}_{4}\right)$ & $4.278(90)$ & 0.151 \\
\hline$r\left(\mathrm{C}_{3} \cdots \mathrm{H}_{4}\right)$ & $3.010(102)$ & 0.154 \\
\hline$r\left(\mathrm{O}_{1} \cdots \mathrm{C}_{3}\right)$ & $2.184(7)$ & 0.061 \\
\hline$r\left(\mathrm{O}_{1} \cdots \mathrm{C}_{3 \mathrm{a}}\right)$ & $2.404(9)$ & 0.076 \\
\hline$r\left(\mathrm{O}_{1} \cdots \mathrm{C}_{4}\right)$ & $3.770(10)$ & 0.085 \\
\hline$r(\mathrm{O} \cdots \mathrm{O})$ & $3.637(10)$ & $0.101\}(7)$ \\
\hline$r\left(\mathrm{~N}_{2} \cdots \mathrm{C}_{4}\right)$ & $3.694(10)$ & 0.071 \\
\hline$r\left(\mathrm{~N}_{2} \cdots \mathrm{O}_{6}\right)$ & $4.289(10)$ & 0.084 \\
\hline$r\left(N_{2} \cdots C_{3 a}\right)$ & $2.313(10)$ & 0.062 \\
\hline$r(N \cdots N)$ & $4.576(13)$ & 0.069 \\
\hline$r(\mathrm{~N} \cdots \mathrm{S})$ & $2.661(7)$ & 0.064 \\
\hline$r\left(\mathrm{C}_{3} \cdots \mathrm{C}_{4}\right.$ & $2.597(20)$ & 0.063 \\
\hline$r\left(C_{3} \cdots S\right)$ & $2.592(8)$ & 0.067 \\
\hline
\end{tabular}

${ }^{a}$ Distances $\left(r_{\mathrm{a}}\right)$ and amplitudes $(\eta)$ in $\AA$, angles $\left(\angle_{\alpha}\right)$ in degrees. Values in parentheses are estimated $2 \sigma$. ${ }^{b}$ Quantities in braces refined as a group. 
Table 3. Correlation matrix $(\times 100)$ for parameters of 1,6-dioxa-6a-thiapentalene.

\begin{tabular}{|c|c|c|c|c|c|c|c|c|c|c|c|c|}
\hline & & $\sigma^{a}$ & $r_{1}$ & $r_{2}$ & $r_{3}$ & $r_{4}$ & $r_{5}$ & $\angle 6$ & $\angle 7$ & $\angle 8$ & $I_{9}$ & $l_{10}$ \\
\hline 1 & $r(\mathrm{C}-\mathrm{H})$ & 0.005 & 100 & 29 & -27 & 15 & -19 & 13 & -10 & -7 & -19 & 7 \\
\hline 2 & $r(\mathrm{C}-\mathrm{O})$ & 0.002 & & 100 & -49 & 69 & -43 & -10 & 35 & -14 & -45 & -24 \\
\hline 3 & $r(\mathrm{C}-\mathrm{C})>$ & 0.001 & & & 100 & -28 & -2 & -28 & -13 & 22 & 13 & 17 \\
\hline 4 & $\triangle r(\mathrm{C}-\mathrm{C})$ & 0.007 & & & & 100 & -63 & -61 & 84 & 6 & -58 & -28 \\
\hline 5 & $r(C-S)$ & 0.004 & & & & & 100 & 85 & -66 & -75 & 73 & 14 \\
\hline 6 & $\angle \mathrm{C}_{2}-\mathrm{C}_{3}-\mathrm{C}_{3 \mathrm{a}}$ & 0.21 & & & & & & 100 & -80 & -71 & 58 & 14 \\
\hline 7 & $\angle \mathrm{O}-\mathrm{C}_{2}-\mathrm{C}_{3}$ & 0.24 & & & & & & & 100 & 27 & -55 & -28 \\
\hline 8 & $\angle \mathrm{C}_{3}-\mathrm{C}_{3 \mathrm{a}}-\mathrm{S}$ & 0.17 & & & & & & & & 100 & -44 & 4 \\
\hline 9 & $1(\mathrm{O}-\mathrm{S})$ & 0.003 & & & & & & & & & 100 & 18 \\
\hline 10 & $/(\mathrm{O}-\mathrm{O})$ & 0.006 & & & & & & & & & & 100 \\
\hline
\end{tabular}

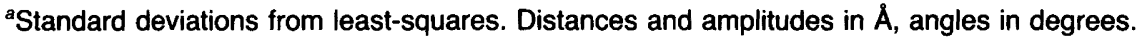

are shown in Figs. 2 and 3. The individual curves and backgrounds are available from the authors on request. The electron scattering amplitudes and phase shifts were calculated analytically using a program originally written by Yates, ${ }^{20} \mathrm{em}$ ploying Hartree-Fock potentials for $\mathrm{C}, \mathrm{N}, \mathrm{O}$ and $\mathrm{S}^{21}$ and using molecular bonded potentials for $\mathrm{H}^{22}$

\section{Structure analysis}

Experimental radial distribution (RD) curves were calculated from composites of the experimental intensity curves. The RD curves are shown in Figs. 4 and 5. Microwave spectroscopy investigations have shown that both DOTP and DADOTP are planar molecules, ${ }^{7,8}$ and that the molecules probably have $C_{2 v}$ symmetry. Leastsquares refinements ${ }^{23}$ of the structures were made for both molecules by simultaneously fitting a single theoretical intensity curve to the two average experimental curves, and the three calculated rotational constants to the experimental ones. Assuming a planar $C_{2 v}$ structure, the geometry of DOTP can be described by ten parameters, in our refinements taken as: $r(\mathrm{C}-\mathrm{H})$, $r(\mathrm{C}-\mathrm{O}),\left\langle r(\mathrm{C}-\mathrm{C})>=0.5\left[r\left(\mathrm{C}_{2}-\mathrm{C}_{3}\right)+r\left(\mathrm{C}_{3}-\mathrm{C}_{3 \mathrm{a}}\right)\right]\right.$, $\Delta r(\mathrm{C}-\mathrm{C})=r\left(\mathrm{C}_{3}-\mathrm{C}_{3 \mathrm{a}}\right)-r\left(\mathrm{C}_{2}-\mathrm{C}_{3}\right), r(\mathrm{C}-\mathrm{S}), \angle \mathrm{C}_{3}-$ $\mathrm{C}_{3 \mathrm{a}}-\mathrm{S}, \angle \mathrm{C}_{2}-\mathrm{C}_{3}-\mathrm{C}_{3 \mathrm{a}}, \angle \mathrm{O}-\mathrm{C}_{2}-\mathrm{C}_{3}, \angle \mathrm{C}_{2}-\mathrm{C}_{3}-\mathrm{H}$ and $\angle \mathrm{C}_{3}-\mathrm{C}_{2}-\mathrm{H}$. The two $\mathrm{C}-\mathrm{C}-\mathrm{H}$ angles could not be determined very well in the refinements and they were therefore kept constant at a reasonable value in the final refinement. Even with the microwave rotational constant included in the re-

Table 4. Correlation matrix $(\times 100)$ for parameters of 1,6-dioxa-2,5-diaza-6a-thiapentalene.

\begin{tabular}{|c|c|c|c|c|c|c|c|c|c|c|c|c|c|}
\hline & & $\sigma^{a}$ & $r_{1}$ & $r_{2}$ & $r_{3}$ & $r_{4}$ & $r_{5}$ & $\angle_{6}$ & $\angle_{7}$ & $\angle_{8}$ & $\angle_{9}$ & $I_{10}$ & $l_{11}$ \\
\hline 1 & $r(\mathrm{C}-\mathrm{H})$ & 0.010 & 100 & 45 & 23 & -44 & -48 & -39 & 43 & -35 & -16 & -25 & -17 \\
\hline 2 & $r(N-O)$ & 0.006 & & 100 & 73 & -99 & -53 & -39 & 83 & 20 & -59 & -34 & -11 \\
\hline 3 & $r(\mathrm{C}-\mathrm{C})$ & 0.002 & & & 100 & -74 & -69 & -8 & 40 & 43 & -38 & -37 & -15 \\
\hline 4 & $r(\mathrm{C}-\mathrm{N})$ & 0.008 & & & & 100 & 52 & 38 & -82 & -25 & 59 & 33 & 10 \\
\hline 5 & $r(\mathrm{C}-\mathrm{S})$ & 0.003 & & & & & 100 & 21 & -12 & -20 & -17 & 52 & -4 \\
\hline 6 & $\angle \mathrm{N}-\mathrm{C}-\mathrm{H}$ & 3.00 & & & & & & 100 & -10 & -13 & -17 & 19 & -22 \\
\hline 7 & $\angle \mathrm{N}-\mathrm{C}-\mathrm{C}$ & 0.26 & & & & & & & 100 & -13 & -84 & -10 & -14 \\
\hline 8 & $\angle \mathrm{O}-\mathrm{N}-\mathrm{C}$ & 0.13 & & & & & & & & 100 & -6 & -18 & -17 \\
\hline 9 & $\angle \mathrm{C}-\mathrm{C}-\mathrm{S}$ & 0.18 & & & & & & & & & 100 & -5 & 26 \\
\hline 10 & $1(\mathrm{O}-\mathrm{S})$ & 0.002 & & & & & & & & & & 100 & 4 \\
\hline 11 & $1(\mathrm{O}-\mathrm{O})$ & 0.004 & & & & & & & & & & & 100 \\
\hline
\end{tabular}

aStandard deviations from least-squares. Distances and amplitudes in $\AA$, angles in degrees. 
finements, several different models gave about equally good fits to the experimental data. The parameter most difficult to determine was $\Delta r$ (C-C). Values for this parameter ranging from 0.00 to $0.05 \AA$ gave about the same fit. Unsymmetric models with different values for the two $\mathrm{O}-\mathrm{S}$ bond lengths were also tested, and although a small difference between the two bonds cannot be excluded completely, the best fit was obtained with the symmetric model.

For DADOTP, nine geometrical parameters were used in the least-squares refinements: $r(\mathrm{C}-\mathrm{H}), r(\mathrm{~N}-\mathrm{O}), r(\mathrm{C}-\mathrm{C}), r(\mathrm{C}-\mathrm{N}), r(\mathrm{C}-\mathrm{S}), \angle \mathrm{C}_{3}-$ $\mathrm{C}_{3 \mathrm{a}}-\mathrm{S}, \angle \mathrm{N}-\mathrm{C}-\mathrm{H}, \angle \mathrm{N}-\mathrm{C}-\mathrm{C}$ and $\angle \mathrm{O}-\mathrm{N}-\mathrm{C}$. For both molecules, most of the vibrational amplitudes were kept constant at values calculated from valence force fields. ${ }^{9}$ These force fields were also used to calculate perpendicular amplitude corrections and they are available from the authors on request. For DADOTP, unsymmetric models with two different $\mathrm{O}-\mathrm{S}$ bond lengths were also tested. The conclusion reached here was the same as for DOTP, viz. that the best agreement was obtained with a symmetric model, but that small deviations could not be completely ruled out.

The final results of the refinements are given in Tables 1 and 2, and the correlation matrices for the parameters are shown in Tables 3 and 4 .

\section{Discussion}

The electron diffraction (ED) investigations have shown that both DOTP and DADOTP are planar molecules with $C_{2}$, symmetry or nearly so. This is in agreement with earlier observations. ${ }^{5,7-9}$ The final structural parameters for DOTP and DADOTP are given in Tables 1 and 2, respectively. Comparison of the two molecules shows that the effect of $\mathrm{N}$-ring substitution is rather pronounced. The largest changes occur for the $\mathrm{S}-\mathrm{O}$ and $\mathrm{C}-\mathrm{S}$ bonds, which are shortened by $0.038 \AA$ and $0.056 \AA$, respectively. The unusually short $\mathrm{C}-\mathrm{S}$ bond observed previously for DADOTP in the solid state ${ }^{5}$ is thus reproduced in the gas phase. The shortening of the O-S bonds therefore seems to be accompanied by a more pronounced double-bond character of the $\mathrm{C}-\mathrm{S}$ bond. This investigation thus supports the evidence for a thiapentalene structure which is closer to a localized form than observed previously. The largest change in bond angles occurs for $\angle \mathrm{C}-\mathrm{N}-\mathrm{O}$, which is lowered by $4.6^{\circ}$, probably as a result of nitrogen lone-pair repulsion. The observed decrease is, however, partly compensated for by an increase in $\angle \mathrm{C}-\mathrm{C}-\mathrm{N}$.

For both molecules, the vibrational amplitude for the $\mathrm{S}-\mathrm{O}$ bond is significantly larger than expected for a regular bond, while the amplitude for the $\mathrm{O}-\mathrm{O}$ distances have more normal values. The same effect was also observed for 1,6,6atrithiapentalene ${ }^{3}$ and was interpreted at that time as evidence of the "bell-clapper" effect. ${ }^{7}$ The vibrational amplitude for the S-S and S-O bonds becomes smaller as we go from TTP to DOTP to DADOTP. This variation in vibrational amplitude may be related to the observed structural parameters in a simple manner.

As discussed earlier, the potential of the "bellclapper" motion of the $S_{6 a}$ atom is wide and $U$ shaped around the equilibrium position. ${ }^{11}$ This is due to the rather weak three-center bonding in this region. Since the potential is very flat, the splittings between vibrational energy levels are small. The vibrational amplitude of the $X_{1}-S_{6 a}$ bond, $l\left(\mathrm{X}_{1}-\mathrm{S}_{6 \mathrm{a}}\right)$, is therefore directly determined by the width, $\Delta X$, of the potential around the equilibrium position, and may be calculated from eqn. (1).

$$
l\left(\mathrm{X}_{1}-\mathrm{S}_{6 \mathrm{a}}\right)=k \cdot \Delta X
$$

In eqn. (1) $\mathrm{k}$ depends on the approximations involved in estimation of $\Delta X$. As a first approximation, $\Delta X$ may be taken as twice the difference between the observed $\mathrm{X}_{1}-\mathrm{S}_{\mathrm{fa}}$ bond length, $L$, and the corresponding $\mathrm{X}_{1}-\mathrm{S}_{6 \mathrm{a}}$ single bond:

Table 5. Comparison of observed vibrational amplitudes, $/\left(X_{1}-S_{6 a}\right)$, and widths of potential curves, $\Delta X$, estimated from structural data.

\begin{tabular}{|c|c|c|c|c|}
\hline Molecule ${ }^{a}$ & $X_{1}-S_{6 a} / \AA$ & $\Delta X^{b} / \AA$ & $/\left(\mathrm{X}_{1}-\mathrm{S}_{6 \mathrm{a}}\right) / \AA \AA$ & $k^{c}$ \\
\hline TTP & 2.33 & 0.46 & 0.138 & 0.30 \\
\hline DOTP & 1.87 & 0.32 & 0.104 & 0.33 \\
\hline DADOTP & 1.83 & 0.24 & 0.086 & 0.35 \\
\hline
\end{tabular}

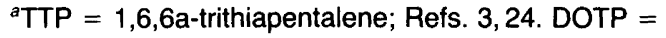
1,6-dioxa-6a-thiapentalene; this work. DADOTP = 2,5-diaza-1,6-dioxa-6a-thiapentalene; this work. ${ }^{b} \Delta X=2\left[L-\left(R_{1}+R_{6 \mathrm{a}}\right)\right]$, where $L=\mathrm{X}_{1}-\mathrm{S}_{6 \mathrm{a}}$ distance and $R_{1}$ and $R_{6 \mathrm{a}}$ are the respective single-bond radii. $R$ is $1.05 \AA$ for $S$ (Ref. 25) and $0.66 \AA$ for $O$ (Ref. 26). ${ }^{c}$ Calculated from $/\left(X_{1}-S_{6 a}\right)=k \cdot \Delta X$. 
Table 6. Geometry of 1,6-dioxa-6a-thiapentalene and some related molecules. ${ }^{a}$

\begin{tabular}{|c|c|c|c|c|}
\hline $\begin{array}{l}\text { Method } \\
\text { Ref. }\end{array}$ & $\begin{array}{l}\text { ED } \\
\text { This work }\end{array}$ & $\begin{array}{l}\text { X-ray } \\
6\end{array}$ & $\begin{array}{l}\text { ED } \\
\text { This work }\end{array}$ & $\begin{array}{l}\text { X-ray } \\
5\end{array}$ \\
\hline Parameter & $\begin{array}{l}\text { 1,6-dioxa-6a- } \\
\text {-thiapentalene }\end{array}$ & $\begin{array}{l}\text { 2,5-dimethyl- } \\
\text {-1,6-dioxa-6a- } \\
\text {-thiapentalene }\end{array}$ & $\begin{array}{l}\text { 2,5-diaza- } \\
\text {-1,6-dioxa-6a- } \\
\text {-thiapentalene }\end{array}$ & $\begin{array}{l}\text { 2,5-diaza- } \\
\text {-1,6-dioxa-6a- } \\
\text {-thiapentalene }\end{array}$ \\
\hline$r(\mathrm{O}-\mathrm{S})$ & $1.865(6)$ & $1.873(4)$ & $1.827(8)$ & $1.852(4)$ \\
\hline$r(\mathrm{C}-\mathrm{S})$ & $1.752(16)$ & $1.732(8)$ & $1.696(12)$ & $1.683(8)$ \\
\hline$r(\mathrm{O}-\mathrm{N})$ & - & - & $1.325(26)$ & $1.350(8)$ \\
\hline$r(\mathrm{C}-\mathrm{N})$ & - & - & $1.329(32)$ & $1.309(12)$ \\
\hline$r(\mathrm{O}-\mathrm{C})$ & $1.310(9)$ & $1.326(8)$ & - & - \\
\hline$r\left(\mathrm{C}_{2}-\mathrm{C}_{3}\right)$ & $1.375(17)$ & $1.371(8)$ & - & - \\
\hline$r\left(\mathrm{C}_{3}-\mathrm{C}_{3 \mathrm{a}}\right)$ & $1.397(15)$ & $1.390(6)$ & $1.411(10)$ & $1.407(10)$ \\
\hline$\angle 1-6 a-3 a$ & $87.1(3)$ & $87.0(2)$ & $85.1(16)$ & $86.0(4)$ \\
\hline$\angle 6 a-3 a-3$ & $112.8(5)$ & $113.9(4)$ & $112.9(5)$ & $113.5(6)$ \\
\hline$\angle 2-3-3 a$ & $113.2(6)$ & $113.4(6)$ & $115.3(8)$ & 116.7(6) \\
\hline$\angle 1-2-3$ & $115.6(7)$ & $115.0(6)$ & $111.0(4)$ & 111.2(6) \\
\hline$\angle 2-1-6 a$ & $111.2(6)$ & $110.7(2)$ & $114.6(8)$ & $113.0(4)$ \\
\hline$\angle 1-6 a-6$ & $174.3(6)$ & $173.9(2)$ & $172.3(8)$ & $171.5(4)$ \\
\hline
\end{tabular}

${ }^{2}$ Distances in $\AA$ and angles in degrees. Values in parentheses are 2o. For atom numbering, see Fig. 1.

$\Delta X=2\left[L-\left(R_{1}+R_{6 a}\right)\right]$.

Here, $R_{1}$ and $R_{6 \mathrm{a}}$ denote the respective singlebond radii.

Table 5 compares the observed vibrational amplitudes with $\Delta X$ for TTP and the two dioxathiapentalene molecules studied here. It is seen that $k$ is very nearly constant for the three compounds studied by electron diffraction, and that the vibrational amplitude is indeed approximately proportional to the "excess" bond length in the three-center sequence. It should be noted, however, that $l\left(\mathrm{O}_{1}-\mathrm{S}_{6 \mathrm{a}}\right)$ may depend somewhat on the fixed value of the vibrational amplitude for the $\mathrm{C}_{3 \mathrm{a}}-\mathrm{S}_{6 \mathrm{a}}$ distance, but since the difference between the two distances is larger than $0.1 \AA$, this correlation should not be too serious.

In Table 6, our results for the geometry of DOTP and DADOTP are compared with the results from X-ray crystallographic studies of DADOTP and of 2,5-dimethyl-1,6-dioxa-6a-thiapentalene. ${ }^{6}$ For DADOTP, the two investigations agree well for the valence angles, whereas the two sets of bond distances differ rather more. Uncertainties are large, however, for the $r(\mathrm{O}-\mathrm{N})$ and $r(\mathrm{C}-\mathrm{N})$ distances in the ED investigation. The distance $r(\mathrm{O}-\mathrm{S})$ seems to be significantly larger in the crystal than in the gas phase. A similar shortening of the $\mathrm{S}-\mathrm{S}$ bond in the gas phase was observed for TTP. ${ }^{3}$

For DOTP, no X-ray investigation has been made, but the results for the dimethyl-substituted compound $^{6}$ are in good agreement with our gas phase results. Here, the difference between the two O-S bonds is only marginal for the two phases.

Electron diffraction is not a well-suited method for determination of bond distances which have almost, but not quite, the same value. The large uncertainties in $r\left(\mathrm{C}_{2}-\mathrm{C}_{3}\right)$ and $r\left(\mathrm{C}_{3}-\mathrm{C}_{3 \mathrm{a}}\right)$ illustrate this point. The average carbon-carbon distance is, however, determined very accurately. We obtained the best result with $\Delta r(\mathrm{C}-\mathrm{C})=r\left(\mathrm{C}_{3}-\mathrm{C}_{3 \mathrm{a}}\right)$ $-r\left(\mathrm{C}_{2}-\mathrm{C}_{3}\right)=0.022(30) \AA$. This is in good agreement with the $\mathrm{X}$-ray results for 2,5-dimethyl-1,6-dioxa-6a-thiapentalene $[\Delta r(\mathrm{C}-\mathrm{C})=$ $0.019 \AA]$. However, in a ${ }^{1} \mathrm{H}$ NMR study in a nematic phase, ${ }^{9}$ the best agreement with the experimental data was obtained with $\Delta r(\mathrm{C}-\mathrm{C})=$ $0.0 \AA$. The average $\mathrm{C}-\mathrm{C}$ distance obtained from ED $[<r(\mathrm{C}-\mathrm{C})\rangle=1.386(5) \AA]$ is in excellent agreement with the NMR results ${ }^{9}[\langle r(\mathrm{C}-\mathrm{C})\rangle=$ 1.389(8) A]]. Both for DOTP and DADOTP, the rotational constants ${ }^{7.8}$ determined from micro- 
wave spectroscopy were included as experimental data in the ED analysis, and our final models gave calculated rotational constants in good agreement with the experimental values. For DOTP, the experimental values are: $A_{\mathrm{z}}=4231.9$, $B_{\mathrm{z}}=1677.2$ and $C_{\mathrm{z}}=1201.5$, all in $\mathrm{MHz}$, and the calculated values are: $A_{\mathrm{z}}=4233.8, B_{\mathrm{z}}=1675.6$ and $C_{\mathrm{z}}=1200.5 \mathrm{MHz}$. For DADOTP, the experimental values are: $A_{\mathrm{z}}=4448.2, B_{\mathrm{z}}=1696.7$ and $C_{\mathrm{z}}=1229.0 \mathrm{MHz}$, and the calculated values are: $A_{\mathrm{z}}=4448.5, B_{\mathrm{z}}=1698.7$ and $C_{\mathrm{z}}=1229.3 \mathrm{MHz}$.

\section{References}

1. Hansen, L. K., Hordvik, A. and Sæthre, L. J. J. Chem. Soc., Chem. Commun. (1972) 222.

2. Clark, D. T. Int. J. Sulfur Chem., Part C 7 (1972) 11.

3. Shen, Q. and Hedberg, K. J. Am. Chem. Soc. 96 (1974) 289.

4. Sæthre, L. J., Svensson, S., Mårtensson, N., Gelius, U., Malmquist, P. A., Bassilier, E. and Siegbahn, K. Chem. Phys. 20 (1977) 431.

5. Amundsen, F. A., Hansen, L. K. and Hordvik, A. Acta Chem. Scand., Ser. A 36 (1982) 673.

6. Dalseng, M., Hansen, L. K. and Hordvik, A. Acta Chem. Scand., Ser. A 35 (1981) 645.

7. Larsen, N. W., Nygaard, L., Pedersen, T., Pedersen, C. T. and Davy, H. J. Mol. Struct. 118 (1984) 89.

8. Pedersen, T., Skaarup, S. V. and Pedersen, C. T. Acta Chem. Scand., Ser. B31 (1977) 711.

9. Bjornholm, T., Jacobsen, J. P. and Pedersen, C. T. J. Mol. Struct. 75 (1981) 327.
10. Fægri, K. and Støgård, Å. J. Mol. Struct. 41 (1977) 271.

11. Sæthre, L. J., Mårtensson, N., Svensson, S., Malmquist, P. Å., Gelius, U. and Siegbahn, K. J. Am. Chem. Soc. 102 (1980) 1783.

12. Sæthre, L. J., Malmquist, P. Å., Mårtensson, N., Svensson, S., Gelius, U. and Siegbahn, K. Inorg. Chem. 20 (1981) 399.

13. Reid, D. H. and Webster, R. G. J. Chem. Soc., Perkin Trans. 1 (1975) 775.

14. Zeil, W., Haase, J. and Wegmann, L. Z. Instrumentenkd. 74 (1966) 84.

15. Bastiansen, O., Graber, R. and Wegmann, L. Balzers High Vacuum Rep. 25 (1969) 1.

16. Tamagawa, K., lijima, T. and Kimura, M. J. Mol. Struct. 30 (1976) 243.

17. Hagen, K. and Hedberg, K. J. Am. Chem. Soc. 95 (1973) 1003.

18. Gundersen, G. and Hedberg, K. J. Chem. Phys. 51 (1969) 2500.

19. Hedberg, L. Abstr. 5th Austin Symp. on Gas Phase Molecular Structure, Austin, TX March 1974, p. 37.

20. Yates, A. C. Comput. Phys. Commun. 2 (1971) 175.

21. Strand, T. G. and Bonham, R. A. J.Chem. Phys. 40 (1964) 1686.

22. Stewart, R.F., Davidson, E. R. and Simpson, W. T. J. Chem. Phys. 42 (1965) 3175.

23. Hedberg, K. and Iwasaki, M. Acta Crystallogr. 17 (1964) 529.

24. Hedberg, K. Personal communication.

25. Hordvik, A. Acta Chem. Scand. 20 (1966) 1885.

26. Pauling, L. Nature of the Chemical Bond, 3rd ed., Cornell University Press, New York 1960.

Received June 24, 1987. 